\title{
Análisis molecular de las relaciones entre hiperlipidemia y fibrosis vascular.
}

\author{
Lucía Serrano-García ${ }^{1,2}$, Ana Asenjo-Bueno², Kevin Henández-López ${ }^{2}$, Elena Alcalde-Estévez³, \\ Patricia Plaza², Patricia Sosa ${ }^{3}$, Gemma Olmos ${ }^{3,4}$, María Piedad Ruíz-Torres ${ }^{3,4}$, \\ Susana López Ongil', 4 \\ 1. Unidad de Bioquímica y Biología Molecular, Departamento de Biología de Sistemas, Facultad de Medicina y Ciencias \\ de la Salud, Universidad de Alcalá, 28871 Alcalá de Henares, Madrid, España. 2. Fundación para la Investigación \\ Biomédica del Hospital Universitario Príncipe de Asturias, Alcalá de Henares, Madrid, España. 3. Dpto. Biología de \\ Sistemas, Universidad de Alcalá, Alcalá de Henares, Madrid, España. 4. Instituto Reina Sofía de Investigación \\ Nefrológica (IRSIN) y Red Renal (REDinREN) del ISCIII, Madrid, España.
}

Palabras clave: Hiperlipidemia; OxLDL; fibrosis vascular; NFkB; ET-1; ROS

\section{Resumen}

La hiperlipidemia es uno de los desórdenes metabólicos más implicados en enfermedades cardiovasculares como la aterosclerosis que cursa con un aumento de LDL oxidadas (OxLDL) en sangre. El objetivo del estudio fue establecer la relación entre hiperlipidemia y fibrosis vascular, evaluando los mecanismos implicados. Para ello, se incubaron células endoteliales con OxLDL encontrando un aumento tanto en la expresión de fibronectina como en la producción de radicales libres. Las OxLDL revelaron la activación del factor de transcripción NFkB vía producción de radicales libres. Además, experimentos con EMSA confirman que el factor NFkB está implicado directamente en el aumento de la expresión de fibronectina estimulado por las OxLDL en células endoteliales. Por otro lado, las OxLDL son capaces de inducir la expresión del enzima conversor de endotelina-1 y la producción de endotelina-1 (ET-1). La ET-1 sintetizada en células endoteliales se libera y llega a otros tipos celulares. Por tanto, se analizó el efecto directo de la ET-1 en células musculares lisas (CML). La ET-1 también estimula fibrosis en CML medida como expresión de la proteína pro-fibrótica CTGF y las proteínas de MEC, fibronectina y colágeno I. La ET-1 también favorece la producción de radicales libres. El efecto de la ET-1 sobre la fibrosis fue específico de su unión al receptor ETA presente en CML, porque el antagonista específico BQ123 bloqueó completamente el efecto de la ET-1. En conclusión, durante la aterosclerosis se favorecerían los procesos de fibrosis tanto a nivel endotelial por las OxLDL como a nivel muscular por la ET-1 generada por ellas, que podría ser la causa de la disfunción vascular presente en la aterosclerosis.

Cita: Serrano-García, Lucía; Asenjo-Bueno, Ana; Henández-López, Kevin; Alcalde-Estévez, Elena;

Plaza, Patricia; Sosa, Patricia; Olmos, Gemma; Ruíz-Torres, María Piedad; López Ongil, Susana (2019)

Análisis molecular de las relaciones entre hiperlipidemia y fibrosis vascular. dianas 8 (2): e201909fa06. ISSN

1886-8746 (electronic) journal.dianas.e201909fa06 http://www3.uah.es/dianas?e201909fa06.

URI http://hdl.handle.net/10017/15181

Copyright: @ Serrano-García L, Asenjo-Bueno A, Henández-López K, Alcalde-Estévez E, Plaza P, Sosa P.

Olmos G, Ruíz-Torres MP, López-Ongil S. Algunos derechos reservados. Este es un artículo open-access

distribuido bajo los términos de una licencia de Creative Commons Reconocimiento-NoComercial-

SinObraDerivada 4.0 Internacional. http://creativecommons.org/licenses/by-nc-nd/4.0/

\section{Introducción}

La hiperlipidemia es uno de los desórdenes metabólicos con más prevalencia en el mundo y en especial en países desarrollados. Se define como un aumento de la concentración de lípidos en sangre [1]. Estos lípidos circulan unidos a proteínas, denominándose lipoproteínas, entre las que encontramos las lipoproteínas de baja densidad (LDL), las cuales son susceptibles de sufrir modificaciones como la oxidación dando lugar a las LDL oxidadas (OxLDL) $[2,3]$. Estas OxLDL están implicadas en procesos inflamatorios, disfunción endotelial y remodelación de la matriz extracelular (MEC) [4]. Todos estos eventos están fuertemente implicados en la patogenia de la aterosclerosis, siendo la hiperlipidemia uno de los principales factores de riesgo de enfermedad cardiovascular $[5,6]$.

La aterosclerosis es una enfermedad progresiva y una de las principales causas de muerte en países desarrollados. Consiste en un trastorno inflamatorio que cursa con formación de placas de ateroma en las paredes arteriales. Estas se desencadenan por acumulación de lípidos (OxLDL) que generan disfunción endotelial, seguido de proliferación y migración de células del músculo liso procedentes de la túnica media, así como aumento de fibroblastos y adipocitos en la adventicia, todo ello sumado al reclutamiento de células del sistema inmune al endotelio (especialmente macrófagos) como consecuencia de la liberación de diversas moléculas quimioatrayentes por parte de las células vasculares [7,8]. La placa aterosclerótica formada reduce el diámetro y elasticidad del vaso y, por tanto, también el flujo sanguíneo.

Si el depósito de OxLDL aumenta en el interior de los macrófagos, estos sufren apoptosis y se produce la rotura de la placa, originando un trombo capaz de obstruir la arteria y dar lugar a un evento cardiovascular $[9,10]$. 
Uno de los procesos implicados en la patogenia de la aterosclerosis es la fibrosis, que consiste en una pérdida del equilibrio entre síntesis y degradación de la MEC, generando daño tisular. Se produce en respuesta a un daño al que sigue una fase inflamatoria y una de reparación o cicatrización no fisiológica, dando lugar a un aumento de la deposición de proteínas de MEC que sustituyen al tejido inicial [10]. Entre ellas, podemos encontrar factores profibróticos como el factor de crecimiento transformante $\beta$ (TGF- $\beta$ ) o el factor de crecimiento del tejido conectivo (CTGF), ambos estimulan la síntesis de proteínas de MEC, adquiriendo especial interés el colágeno I y la fibronectina (FN). Además, disminuyen la capacidad de degradación de MEC por parte de las metaloproteinasas de matriz (MMPs). La fibrosis está asociada a múltiples enfermedades, locales o sistémicas, entre las que se encuentran las enfermedades cardiovasculares $[11,12]$.

El estrés oxidativo también forma parte de la patología aterosclerótica. Es generado por un aumento de radicales libres como consecuencia de un desequilibrio con los sistemas antioxidantes. Entre los radicales libres encontramos las especies reactivas del oxígeno (ROS) y del nitrógeno (RNS), que son producto del metabolismo celular y pueden reaccionar con otras moléculas del organismo como el ADN y las proteínas. En condiciones de hiperlipidemia, pueden oxidar las LDL, transformándolas en OxLDL y favoreciendo la aterogénesis [13]. A su vez, las OxLDL, son capaces de activar sistemas productores de radicales libres, como la NADPH oxidasa, retroalimentando el estrés oxidativo.

Además, el aumento de radicales libres, también se ha relacionado con fibrosis, ya que son capaces de promover la proliferación y diferenciación de fibroblastos, así como la activación de proteínas profibróticas como el TGF- $ß$ o el CTGF [14], por medio de la estimulación de proteasas capaces de liberar a estos factores de sus proteínas inhibitorias. Este proceso se ve retroalimentado con el hecho de que, a su vez, el TGF- $\beta$ también es capaz de activar sistemas productores de radicales libres [12, 15].

Los radicales libres también están relacionados con la inflamación, ya que son capaces de activar factores proinflamatorios como el NFkB [18]. Este factor, puede estar formado por distintas subunidades, en este caso estudiaremos el complejo canónico p50/p65. Se encuentra de manera constitutiva en el citoplasma unido a una proteína inhibitoria (IkB). Cuando aparece un estímulo de NFkB, se activa la IKK o quinasa de IkB, que fosforila IkB disociándose del complejo para ser degradada por el proteosoma, permitiendo la translocación del dímero NFkB (p50/p65) al núcleo, así como su fosforilación para activarse [19, 20]. Especies oxidantes como el peroxinitrito, el agua oxigenada o el ión superóxido, son capaces de activar la IKK permitiendo que NFkB entre al núcleo para unirse a promotores de distintos genes relacionados con inflamación, proliferación y fibrosis, todos ellos implicados en la patología aterosclerótica [21].

Dos de los genes cuya expresión es activada por NFkB es el de la prepro-ET-1 [22] y el de la enzima conversora de ET-1 (ECE-1) [9], ambos genes son fundamentales para la síntesis de ET-1 que es un péptido secretado principalmente por las células endoteliales. Existen 3 isoformas, siendo la ET-1 la isoforma mayoritaria y a la que nos referiremos a partir de ahora. La ET-1 es uno de los vasoconstrictores más potentes y es inducida por estímulos como hipoxia o isquemia [23]. Promueve la síntesis de algunas moléculas vasoconstrictoras como angiotensina, catecolaminas y otras vasodilatadoras como el óxido nítrico (NO), el cual inhibe a la ET-1 actuando como un regulador negativo. Su poder vasoconstrictor también es debido a que promueve la liberación de calcio y activa quinasas capaces de fosforilar la cadena ligera de miosina.

La ET-1 se sintetiza principalmente por células del endotelio vascular, aunque también la producen las células musculares lisas (CML), el riñón, pulmón, corazón, hígado y neuronas entre otros. En primer lugar, se genera la prepro-ET-1 que por acción de una endopeptidasa se forma la BigET-1, péptido inactivo. Posteriormente, la BigET-1 por acción específica de la ECE-1 se transforma en ET-1, la forma madura y activa. La ET ejerce sus acciones tras unirse específicamente a su receptor de 7 dominios transmembrana unido a proteínas $\mathrm{G}$. Existen dos receptores típicos $\mathrm{ET}_{\mathrm{A}}$ y $\mathrm{ET}_{\mathrm{B}}$, predominando el $\mathrm{ET}_{\mathrm{A}}$ en células musculares, siendo responsable de su efecto contráctil, mitogénico y proliferativo, y el $\mathrm{ET}_{\mathrm{B}}$ es mayoritario en células endoteliales y media su efecto vasodilatador generando NO y retira de la circulación el exceso de ET-1, compensando, por tanto, su efecto contráctil. En condiciones fisiológicas se encarga junto con el NO, de mantener el tono vascular.

También es capaz de inducir proliferación celular por vía de las MAP quinasas, así como la expresión de varios genes [24]. Sin embargo, alteraciones en los niveles normales de ET-1 han sido relacionadas con patologías como hipertensión, hipertrofia, diabetes y aterosclerosis. De hecho, los pacientes con aterosclerosis presentan niveles elevados de ET-1 y ésta podría estar implicada en la fase inflamatoria temprana, ya que junto con las OxLDL produce un aumento de moléculas de adhesión y quimiocinas, promoviendo la migración de macrófagos y su diferenciación al fenotipo M1, que se corresponde con el fenotipo inflamatorio [25]. Por otro lado, induce la síntesis de proteínas de MEC como FN, y también potencia la acción del TGF-ß y del PDGF [26-28]. 


\section{Materiales y métodos}

\section{Cultivos celulares}

Se han utilizado dos tipos celulares, ambos humanas, células endoteliales (EA, EA.hy926) procedentes de ATCC y células musculares lisas (CML, HA-VSMC) procedentes del cultivo primario de aortas de donantes humanos. El medio utilizado para crecer las EA fue DMEM de ATCC (St. Louis, MO, USA) y para las CML, DMEM de SIGMA (Manassas, VA, USA), ambos son medios con alta glucosa y se suplementan con suero fetal bovino (FBS) al 10\%, y con antibióticos $100 \mathrm{U} / \mathrm{ml}$ de penicilina y $100 \mu \mathrm{g} / \mathrm{ml}$ de estreptomicina. Las células se dejan crecer a $37^{\circ} \mathrm{C}$ en un incubador con $5 \%$ de $\mathrm{CO}_{2}$.

La amplificación se realiza cuando alcanzan el $80-100 \%$ de confluencia, utilizando Trypsina-EDTA para levantar las células de la placa y sembrarlas en otras placas en función del experimento a realizar. En el caso de las células endoteliales, a las placas se les añade gelatina al 0,2\%. Antes de la realización del experimento, incubación de EA con LDL oxidadas (OxLDL) o CML con ET-1, las células se lavaron con PBS (phosphate buffered saline) para sustituir el medio por otro sin FBS con el fin de frenar el crecimiento, detener todas las células en la misma fase y así tenerlas quiescentes.

\section{Oxidación de LDL}

Las lipoproteínas de baja densidad (LDL) procedentes de plasma humano (SIGMA) fueron oxidadas durante $48 \mathrm{~h}$ con $25 \mu \mathrm{M}$ de $\mathrm{CuSO}_{4}$, en PBS y agitación. La oxidación se verificó mediante electroforesis en gel Paragon en condiciones no desnaturalizantes. La banda de las OxLDL mostró una migración dos veces más rápida que la de las LDL nativas (Figura 1). La concentración de OxLDL utilizada para realizar los experimentos fue de $50 \mu \mathrm{g} / \mathrm{mL}$.

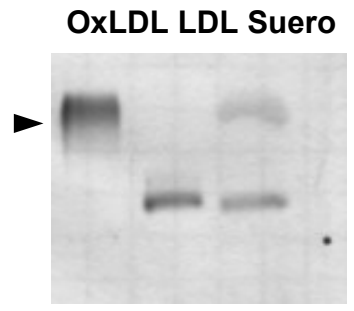

Figura 1.- Electroforesis en gel Paragon para detectar la oxidación de LDL y compararlo con LDL nativas y suero humano.

\section{Medida de la producción de ET-1}

Tras los diferentes tratamientos de EA con OxLDL, se recogieron los sobrenadantes y se liofilizaron, guardándose a $-80^{\circ} \mathrm{C}$ hasta que se realizó el ensayo. La ET-1 se midió con un ELISA comercial de Immuno-Biological Laboratories (IBL Co., Japan) y la absorbancia se registró a 450nm con un lector de placas. Las absorbancias de cada muestra se extrapolaron en los datos de una curva estándar realizada con un estándar de ET-1 conocido.

\section{Análisis de la expresión proteica}

Tras los diferentes tratamientos, se lavan las células con PBS y se añade buffer de lisis $(0.1 \%$ deoxicolato sódico, $150 \mathrm{mM} \mathrm{NaCl}$ EGTA, $1 \mathrm{mM}$ EDTA, $20 \mathrm{mM}$ Tris- $\mathrm{HCl} \mathrm{pH} 7.5,1 \%$ Triton X-100, $10 \mathrm{mM}$ $\mathrm{Na}_{4} \mathrm{P}_{2} \mathrm{O}_{7}$ ) con inhibidor de proteasas para extraer las proteínas totales. El contenido de las placas se raspa y se pasa a un tubo eppendorf para centrifugarlo durante $30 \mathrm{~min}$ a $4^{\circ} \mathrm{C}$ y a $13000 \mathrm{rpm}$, para eliminar los restos celulares. La concentración proteica se mide con un kit de BioRad para poder pinchar una cantidad fija de proteínas de cada muestra en geles SDS-PAGE al 7\% en condiciones reductoras y separar las proteínas por electroforesis a $100 \mathrm{~V}$, y posteriormente transferirlas a una membrana de nitrocelulosa. Después, las membranas se bloquean con leche o BSA al 5\% durante una hora a temperatura ambiente y se lavan con Tween Tris buffered saline (TTBS) (20mM Tris-HCl, pH 7.5, 150mM NaCl, 0.05\% Tween20), para después ser incubadas con los anticuerpos primarios correspondientes (Tabla 1). Para el revelado, se utiliza un kit Supersignal West Pico de Pierce (ThermoFisher) y gracias a la fluorescencia liberada por las proteínas marcadas se impresiona la película autorradiográfica (X-film, Kodak).

La expresión de cada proteína estudiada es corregida en función de la carga, utilizando para ello la GAPDH como gen constitutivo. Para su cuantificación y corrección se analizan las bandas correspondientes a la proteína de interés mediante el software "Image J" (NIH, Bethesta, MD, USA). 


\begin{tabular}{|c|c|c|c|}
\hline Anticuerpo & Casa comercial & Dilución & Incubación \\
\hline Rabbit anti-Colágeno I & Abcam & $1 / 500$ en $3 \%$ BSA & $2 \mathrm{~h} \mathrm{R} / \mathrm{T}$ \\
\hline Rabbit anti-Fibronectina & Abcam & $1 / 1000$ en $0.05 \%$ BSA & $1 \mathrm{~h} \mathrm{R} / \mathrm{T}$ \\
\hline Mouse anti-eNOS & BD Transduction & $1 / 2500$ en $3 \%$ BSA & $1 \mathrm{~h} \mathrm{R} / \mathrm{T}$ \\
\hline Mouse anti-peNOS & BD Transduction & $1 / 2500$ en $3 \%$ BSA & $1 \mathrm{~h} \mathrm{R} / \mathrm{T}$ \\
\hline Rabbit anti-P-NFkB p65 & Cell Signalling & $1 / 100$ en $3 \%$ BSA & $1 \mathrm{~h} \mathrm{R} / \mathrm{T}$ \\
\hline Rabbit anti-NFкB p65 & Santa Cruz & $1 / 1000$ en $3 \%$ BSA & $1 \mathrm{~h} \mathrm{R} / \mathrm{T}$ \\
\hline Mouse anti-P-IкB $\alpha$ & Santa Cruz & $1 / 1000$ en $3 \%$ BSA & $\mathrm{O} / \mathrm{N} 4^{\circ} \mathrm{C}$ \\
\hline Mouse anti-ECE & $*$ & $1 / 500$ en $0.05 \%$ BSA & $\mathrm{O} / \mathrm{N} 4^{\circ} \mathrm{C}$ \\
\hline Mouse anti-GAPDH & Sigma & $1 / 1000 \sin \mathrm{BSA}$ & $\mathrm{O} / \mathrm{N} 4^{\circ} \mathrm{C}$ \\
\hline Mouse anti-PARP & Santa Cruz & $1 / 1000$ en $1.5 \%$ BSA & $\mathrm{O} / \mathrm{N} 4^{\circ} \mathrm{C}$ \\
\hline Rabbit anti-CTGF & Abcam & $1 / 2000$ en $3 \%$ BSA & $\mathrm{O} / \mathrm{N} 4^{\circ} \mathrm{C}$ \\
\hline
\end{tabular}

Tabla 1.- Anticuerpos primarios utilizados en la realización de Western blot. *El anticuerpo monoclonal de ECE-1 (mAb AEC32-236) fue proporcionado por Kohei Shimada de Biological Research Laboratories (Sankyo Co., Ltd. Tokyo, Japan).

\section{Inmunofluorescencia}

Las células fueron cultivadas en placas P12 con coverslips de cristal de $12 \mathrm{~mm}$ recubiertos con gelatina al $0,2 \%$. Al alcanzar una confluencia total, se deprivan durante $24 \mathrm{~h}$ hasta la realización del tratamiento. Tras el tratamiento, las células son fijadas con para-formaldehído al 3,7\% durante 10min y luego, permeabilizadas con Triton X-100 10min. Tras dos lavados con PBS, se bloquea con BSA al 5\%, 1h, para después incubarlas con los anticuerpos primarios (Tabla 2) durante toda la noche a $4^{\circ} \mathrm{C}$. Tras la incubación, se añaden los anticuerpos secundarios, marcados con fluoróforos. Una vez retirado el secundario, los núcleos son teñidos con DAPI durante $20 \mathrm{~min}$, y a continuación se montan los coverslips en un portaobjetos con Prolong Gold antifade reagent. Tras $24 \mathrm{~h}$ en oscuridad, las preparaciones son observadas en un microscopio confocal de fluorescencia (LEICA TCS-SP5 confocal microscope, Leica Microsystems; Wetzlar, Germany).

\begin{tabular}{clll}
\multicolumn{1}{c}{ Anticuerpo } & Casacomercial & Dilución & Incubación \\
\hline Mouse anti-Fibronectina & Abcam & $1 / 100$ en $1 \% \mathrm{BSA}$ & $\mathrm{O} / \mathrm{N} 4^{\circ} \mathrm{C}$ \\
\hline Rabbit anti-Colágeno I & Abcam & $1 / 100$ en $1 \% \mathrm{BSA}$ & $\mathrm{O} / \mathrm{N} 4^{\circ} \mathrm{C}$ \\
\hline
\end{tabular}

Tabla 2.- Anticuerpos primarios utilizados en inmunofluorescencia.

\section{Análisis de producción de radicales libres}

Las células fueron crecidas en placas de $35 \mathrm{~mm}$ con cover de cristal integrado y gelatina al $0,2 \%$. Al alcanzar el $80 \%$ de confluencia son deprivadas $24 \mathrm{~h}$ para realizar el tratamiento posteriormente. La producción de ROS es detectada con una sonda CellROX de Molecular Probes (ThermoFisher, Madrid, España) a una concentración de $5 \mu \mathrm{M}$, añadida en los últimos $30 \mathrm{~min}$ de tratamiento a $37^{\circ} \mathrm{C}$. Posteriormente, las células son fijadas con 3,7\% de para-formaldehído $10 \mathrm{~min}$, y se visualizan in vivo en un microscopio confocal (LEICA TCS-SP5 confocal microcope, Leica Microsystems; Wetzlar, Germany)

\section{Ensayo de retardo en gel (EMSA)}

Los extractos nucleares se obtuvieron mediante el kit NE-PER Nuclear and Cytoplasmic Extraction Reagent (Thermo scientific), y tras cuantificarlos fueron incubados $20 \mathrm{~min}$ con un oligo específico que reconoce la secuencia de unión al factor de transcripción NFkB del promotor de la fibronectina humana (5'-ggg gga gga gaG GGA ACC CCA ggc gcg agc-3'), siguiendo las instrucciones del kit Lightshift 
Chemiluminescent EMSA (Thermo scientific). Las muestras fueron pinchadas en un gel de poliacrilamida tras pre correrlo $30 \mathrm{~min}$ a $100 \mathrm{~V}$ en buffer $0.5 \mathrm{x}$ Tris-borate-EDTA (TBE). Las muestras se dejan correr a $100 \mathrm{~V}$ durante $1 \mathrm{~h}$ y posteriormente, las proteínas son transferidas a una membrana de Nylon durante $30 \mathrm{~min}$, en agitación y a $380 \mathrm{~mA}$. Una vez transferida, la membrana es bloqueada y conjugada con las soluciones del kit, y, por último, son reveladas con luminol y $\mathrm{H}_{2} \mathrm{O}_{2}$ durante $5 \mathrm{~min}$ hasta adquirir la fluorescencia necesaria para impresionar las películas autorradiográficas (X-film, Kodak).

\section{Análisis estadístico}

El análisis estadístico se realizó con el programa Graph Pad prism 5.03 (Graph Pad Software, San Diego, CA, USA). Se consideraron diferencias estadísticamente significativas si la $p<0,05$. El test estadístico aplicado fue una ANOVA con medidas repetidas, seguido de una comparación múltiple con el test Dunnett's o del test Bonferroni. Los datos son expresados como la media \pm s.e.m. de al menos 3 o 4 experimentos independientes, y son dados como medidas arbitrarias densitométricas o de fluorescencia.

\section{Resultados}

\section{Las OxLDL aumentan la expresión de proteínas de MEC a través de la activación de NFkB}

Las células endoteliales (EA) fueron tratadas con una concentración de $50 \mu \mathrm{g} / \mu \mathrm{L}$ de OxLDL a diferentes tiempos de incubación. Se eligió esta dosis de OxLDL ya que había sido puesto a punto por el grupo anteriormente. Las OxLDL inducen la expresión de proteínas de MEC como la FN (Fig. 1A). Además, las OxLDL son capaces de inducir en células endoteliales la producción de radicales libres (Fig. 1B)

Como se sabe que los radicales libres pueden activar factores de transcripción como el NFkB, que a su vez puede regular la transcripción de diferentes genes, nos propusimos estudiar si las OxLDL estaban regulando dicho factor. Para ello, se estudió por Western blot la expresión proteica en citoplasma (Fig. 1C) y núcleo (Fig. 1D) de la subunidad inhibitoria IkB fosforilada (p-IkB) y de la subunidad p65 del NFkB total y fosforilada ( $\mathrm{p}-\mathrm{NFkB}$ ). En primer lugar, se observa cómo las OxLDL inducen una fosforilación de IkB aumentando en citoplasma y reduciéndose en el núcleo, esto da paso a que NFkB se suelte de la subunidad inhibitoria IkB y pueda translocarse al núcleo, de forma que NFkB aumenta progresivamente en núcleo y desaparece del citoplasma. Además, una vez en el núcleo NFkB se activa fosforilándose. Estos datos confirman que OxLDL activa NFkB translocándose al núcleo.

A

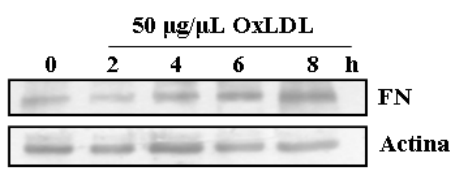

C

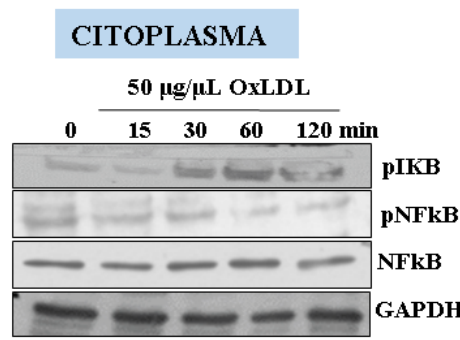

$\mathbf{E}$

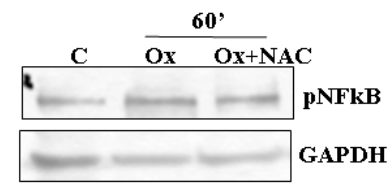

B

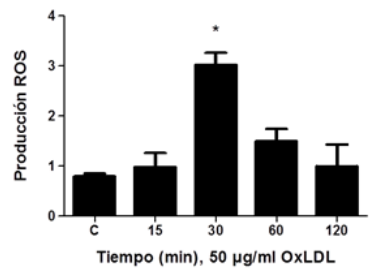

D

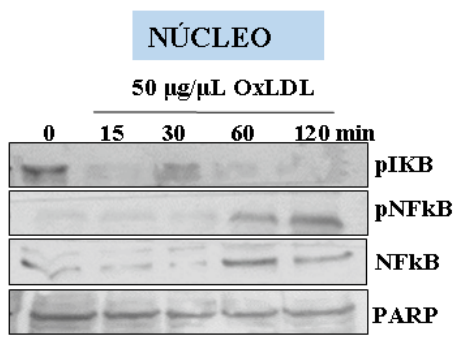

F

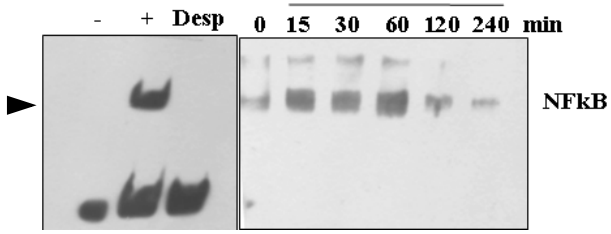

Figura 1.- Mecanismo de regulación de FN inducida por las OxLDL en células endoteliales. A) Expresión de FN. B) Producción de ROS. C) Expresión de NFkB en citoplasma. D) Expresión de NFkB en núcleo. E) Efecto de NAC sobre p-NFkB. F) Unión del factor NFkB al promotor del gen FN por EMSA. Carril (-): corresponde al control sin extracto nuclear y oligo NFkB biotinilado; carril (+): corresponde al control con extracto nuclear y oligo NFkB biotinilado; carril (Desp): corresponde al control con extracto nuclear, oligo NFkB biotinilado y exceso de oligo NFkB no marcado.

A continuación, se evaluó si el estímulo de NFkB inducido por las OxLDL dependía de la producción de radicales libres, para ello, se pretrataron las células con un antioxidante $\mathrm{N}$-acetil-cisteína (NAC, 100 $\mu \mathrm{M})$ para estudiar la expresión de p-NFkB. Las OxLDL inducen fosforilación de NFkB que se revierte 
parcialmente con NAC (Fig. 1E), sugiriendo que su activación depende al menos en parte de la producción de radicales libres.

Por último, ensayos de EMSA confirmaron que NFkB estaba implicado en la transcripción del gen de FN (Fig. 1F). En este caso las células fueron incubadas con OxLDL a tiempos cortos $(15,30,60,120$ y 240 minutos), y posteriormente se extrajeron los núcleos que fueron incubados con un oligo biotinilado que reconocía específicamente la secuencia de NFkB del promotor humano de la FN. La figura 1E muestra a la derecha cómo las OxLDL inducen la unión del oligo al promotor de FN, indicando que las OxLDL inducen la expresión de FN al activar la unión de NFkB a su promotor. El aumento fue máximo a los 60min. A la izquierda de la Fig. 1E se muestran los controles del EMSA, indicando que el efecto es específico de NFkB, ya que se desplaza con un exceso de oligo no marcado para NFkB (Desp).

\section{Las OxLDL inducen expresión de ECE-1 y la producción de ET-1 en células endoteliales}

Las células endoteliales fueron tratadas con $50 \mu \mathrm{g} / \mu \mathrm{L}$ de OxLDL a distintos tiempos. Posteriormente, se analizó la expresión proteica de ECE-1 por Western blot, observando una estimulación entre las 4 y $8 \mathrm{~h}$ (Fig. 2A). Posteriormente, se analizó la producción de ET-1 mediante un ELISA comercial, confirmando un aumento en paralelo de la síntesis de ET-1, que fue significativo entre las 6 y $8 \mathrm{~h}$ (Fig. 2B).

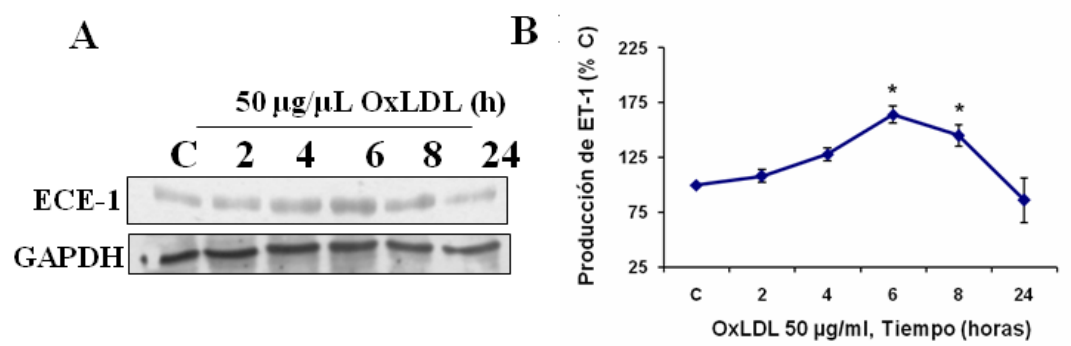

Figura 2.- Efecto de las OxLDL sobre el sistema de ET-1 en células endoteliales humanas. A) Expresión de ECE-1. B) Producción de ET-1.

La ET-1 induce síntesis de proteínas de MEC y la producción de radicales libres en células musculares lisas

$\mathbf{A}$

nM Endotelina 24h

C $\begin{array}{lllll}0,1 & 1 & 5 & 10 & 25\end{array}$

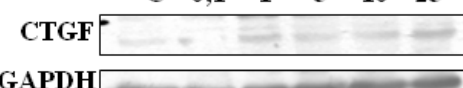

(h) 5nM Endotelina

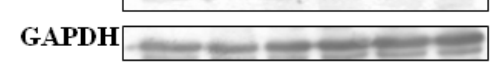

CTGF

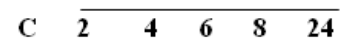

GAPDH $=-\div$

B

nM Endotelina $24 h$

C

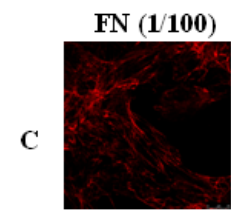

Merge

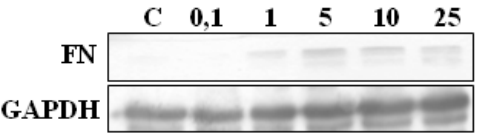

(h) 5 nM Endotelina

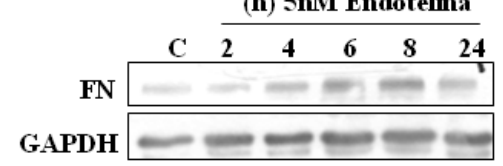

ET
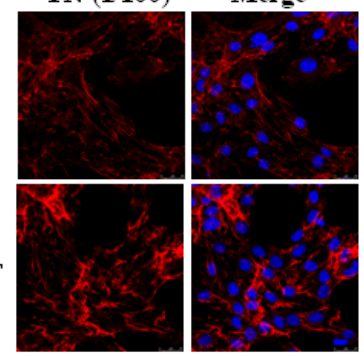

D

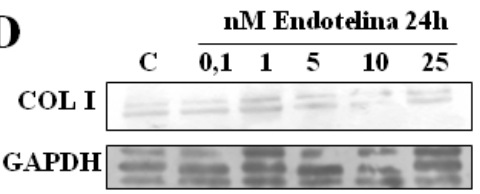

$\mathbf{E}$

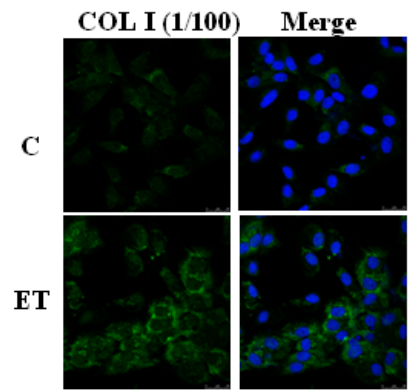

Figura 3.- Efecto de la ET-1 sobre la expresión de proteínas de MEC. A) Expresión de la proteína profibrótica CTGF. B) Expresión de FN por Western blot. C) Expresión de FN por inmunofluorescencia. D) Expresión de colágeno I. E) Expresión de Colágeno I por inmunofluorescencia. Las fotos de la inmunofluorescencia se realizaron en un microscopio confocal 
con un objetivo de 40 aumentos, mostrando los núcleos teñidos con DAPI en azul, la FN en rojo y el

colágeno I en verde.

Los vasos están formados por células endoteliales y células musculares principalmente, puesto que encontramos que las OxLDL inducen la síntesis de ET-1, ésta al liberarse ejerce sus funciones sobre otras células como las CML. Por este motivo, quisimos estudiar el efecto directo de la ET-1 sobre las CML en cuanto a la regulación de las proteínas de MEC. Se estudiaron tres proteínas, FN, colágeno I y CTGF como proteína pro-fibrótica. Para ello, las CML se incubaron con distintas dosis y tiempos de ET-1, y se extrajeron las proteínas que fueron evaluadas por Western blot. Todas las proteínas analizadas CTGF (Fig. 3A), FN (Fig. 3B) y colágeno I (Fig. 3D), aumentaron de forma dosis (ET-1 24h) y tiempo dependiente (ET-1 5nM) en CML. También se evaluó la expresión y locación celular de la FN (Fig. 3C) y del colágeno I (Fig. 3E) por inmunofluorescencia, tras incubar las CML con ET-1 5nM durante 8h. La ET-1 indujo un aumento evidente de todas las proteínas estudiadas, favoreciendo la fibrosis muscular.

A continuación, se analizó la producción de radicales libres en CML incubadas con ET-1 5nM durante distintos tiempos, observando un aumento paulatino con el tiempo que fue significativo a partir de los 30min (Fig. 4).
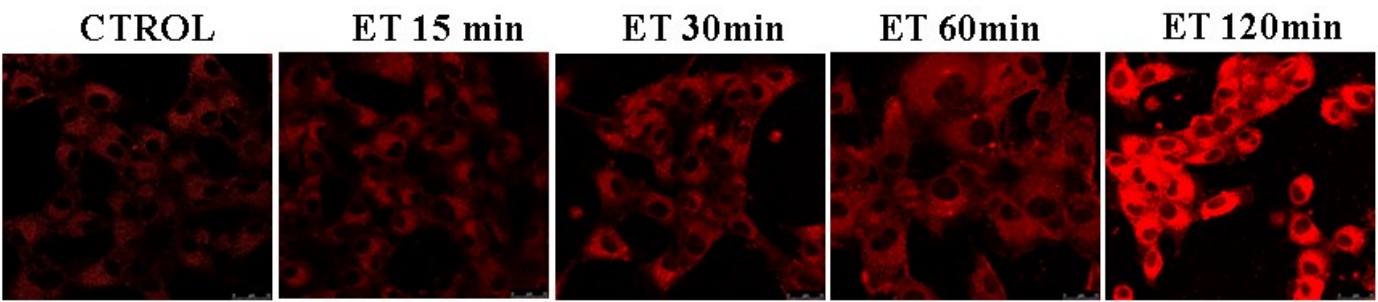

Figura 4.- Efecto de la ET-1 en la producción de especies reactivas de oxígeno en CML.

\section{El receptor $\mathrm{ET}_{\mathrm{A}}$ media el efecto inductor de la $\mathrm{ET}-1$ sobre la fibrosis en $\mathrm{CML}$}

El principal receptor de ET-1 en las CML es el receptor $\mathrm{ET}_{\mathrm{A}}$. Para estudiar si el efecto pro-fibrótico inducido por este péptido sobre las CML, era dependiente y específico de la unión a este receptor, se preincubaron las CML con un antagonista específico del receptor $\mathrm{ET}_{\mathrm{A}}(\mathrm{BQ}-123100 \mathrm{nM})$ una hora antes de añadir la ET-1 5nM durante $8 \mathrm{~h}$. Después se analizaron por Western blot la expresión de FN y de colágeno I, confirmando que el efecto de la ET-1 sobre estas proteínas era específico de su unión al receptor $\mathrm{ET}_{\mathrm{A}}$ porque en presencia de $\mathrm{BQ}-123$ el efecto se revierte (Fig. 5).

A

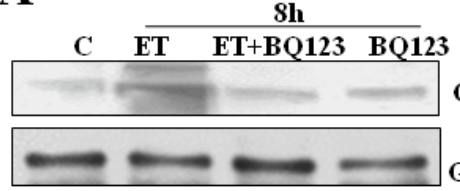

B

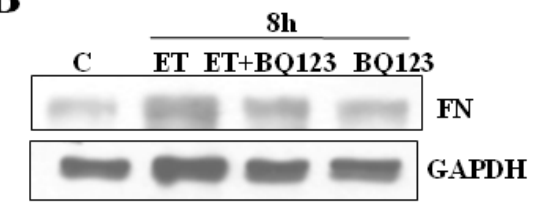

Figura 5.- La fibrosis inducida por ET-1 está mediada por su unión al receptor ET $_{\mathrm{A}}$ en CML. A) Expresión de colágeno I. B) Expresión de fibronectina (FN).

\section{Discusión}

En este estudio hemos logrado establecer una relación en la hiperlipidemia, presente en enfermedades cardiovasculares, y la fibrosis vascular.

Los experimentos realizados en células endoteliales evidenciaron en primer lugar que las OxLDL inducen la expresión de FN y la síntesis de radicales libres. El mecanismo implicado parece ser a través de la activación del factor de transcripción NFkB por parte de los radicales libres generados por las OxLDL. Estos resultados están de acuerdo con la literatura [13], donde observan como las OxLDL son capaces de estimular la síntesis de radicales libres. Además, se demuestra que NFkB regula positivamente la expresión de FN inducida por OxLDL, sugiriendo que la aterosclerosis potencia el desarrollo de fibrosis en el endotelio.

Previos estudios ya reflejaron un aumento del sistema de ET-1 por parte de las OxLDL tanto en células endoteliales como en ratones deficientes en apoE utilizado como modelo de aterosclerosis [9]. De acuerdo con esos resultados, este trabajo también muestra como las OxLDL en células endoteliales humanas aumentan tanto la expresión de ECE-1, como la producción de ET-1. Dado que muchos autores han descrito la comunicación celular existente en aterosclerosis [8], estudiamos el efecto directo de la ET-1 en CML, para simular que lo pasaría en un vaso con aterosclerosis donde las OxLDL inducen síntesis de 
radicales libres, FN y también de ET-1 en el endotelio, y después esa ET-1 ejercería sus efectos sobre otras células próximas como las CML.

La ET-1 estimuló la expresión de la proteína profibrótica CTGF, y de proteínas de MEC como FN y colágeno I de acuerdo con la bibliografía [26-28]. Estas proteínas se han descrito como marcadores de fibrosis por ser factores profibróticos y proteínas de MEC [11,12]. Por tanto, la ET-1 estaría induciendo fibrosis en el músculo liso. Por otro lado, la ET-1 aumenta la producción de radicales libres de forma muy significativa, sugiriendo que éstos podrían estar mediando su efecto sobre la fibrosis. Sin embargo, estos estudios quedan pendientes de ser realizados.

Por último, para comprobar si los efectos observados sobre la inducción de la fibrosis eran específicos de la respuesta de la ET-1 tras la unión a su receptor $\mathrm{ET}_{\mathrm{A}}$ presente en las CML [24], se hicieron experimentos con el antagonista específico de dicho receptor, BQ-123, mostrando la especificidad del efecto. Por tanto, la inhibición del receptor $\mathrm{ET}_{\mathrm{A}}$ es capaz de revertir la fibrosis en músculo liso estimulada por ET-1.

Durante la aterosclerosis existe hiperlipidemia, elevándose así los niveles de OxLDL. Estas OxLDL en células endoteliales en cultivo son capaces de inducir síntesis de radicales libres, responsables de activar al factor de transcripción NFkB, que a su vez al unirse al promotor de algunos genes como el de la FN promueve el proceso de fibrosis en el endotelio. Además, como las OxLDL son capaces de aumentar los niveles de ET-1, péptido que se excreta según se sintetiza, ésta puede actuar en diferentes células como las CML. Esta ET-1 a su vez induce fibrosis al unirse al receptor $\mathrm{ET}_{\mathrm{A}}$ del músculo liso, que también podría estar mediada por la síntesis de radicales libres, puesto que aumentan con la ET-1, pero este mecanismo necesita ser explorado. En conclusión, durante la aterosclerosis se favorecerían los procesos de fibrosis tanto a nivel endotelial por las OxLDL como a nivel muscular por la ET-1 generada por dichas OxLDL, de forma que dicha fibrosis podría ser la causa de la disfunción vascular presente en la aterosclerosis.

\section{Bibliografía}

1. Li, L. and Yang, X., 2018. The Essential Element Manganese, Oxidative Stress, and Metabolic Diseases: Links and Interactions. Oxidative medicine and cellular longevity, 2018.

2. Gebreyes, Y.F., Goshu, D.Y., Geletew, T.K., Argefa, T.G., Zemedu, T.G., Lemu, K.A., Waka, F.C., Mengesha, A.B., Degefu, F.S., Deghebo, A.D. and Wubie, H.T., 2018. Prevalence of high bloodpressure, hyperglycemia, dyslipidemia, metabolic syndrome and their determinants in Ethiopia: Evidences from the National NCDs STEPS Survey, 2015. PloS one, 13(5), p.e0194819.

3. Mitchell, S., Roso, S., Samuel, M. and Pladevall-Vila, M., 2016. Unmet need in the hyperlipidaemia population with high risk of cardiovascular disease: a targeted literature review of observational studies. BMC cardiovascular disorders, 16(1), p.74.

4. Yurdagul, A., Green, J., Albert, P., McInnis, M.C., Mazar, A.P. and Orr, A.W., 2014. $\alpha 5 \beta 1$ Integrin Signaling Mediates Oxidized Low-Density Lipoprotein-Induced Inflammation and Early Atherosclerosis. Arteriosclerosis, thrombosis, and vascular biology, pp.ATVBAHA-114.

5. Dominguez, J.H., Mehta, J.L., Li, D., Wu, P., Kelly, K.J., Packer, C.S., Temm, C., Goss, E., Cheng, L., Zhang, S. and Patterson, C.E., 2008. Anti-LOX-1 therapy in rats with diabetes and dyslipidemia: ablation of renal vascular and epithelial manifestations. American Journal of Physiology-Renal Physiology, 294(1), pp.F110-F119

6. Al Gadban, M.M., Smith, K.J., Soodavar, F., Piansay, C., Chassereau, C., Twal, W.O., Klein, R.L., Virella, G., Lopes-Virella, M.F. and Hammad, S.M., 2010. Differential trafficking of oxidized LDL and oxidized LDL immune complexes in macrophages: impact on oxidative stress. PloS one, 5(9), p.e12534.

7. Mimura, J. and Itoh, K., 2015. Role of Nrf2 in the pathogenesis of atherosclerosis. Free Radical Biology and Medicine, 88, pp.221-232.Mehta, J.L., Chen, J., Hermonat, P.L., Romeo, F. and Novelli, G., 2006. Lectin-like, oxidized low-density lipoprotein receptor-1 (LOX-1): a critical player in the development of atherosclerosis and related disorders. Cardiovascular research, 69(1), pp.36-45.

8. Wang, D., Wang, Z., Zhang, L. and Wang, Y., 2017. Roles of cells from the arterial vessel wall in atherosclerosis. Mediators of inflammation, 2017.

9. Martínez-Miguel, P., Raoch, V., Zaragoza, C., Valdivielso, J.M., Rodríguez-Puyol, M., RodríguezPuyol, D. and López-Ongil, S., 2009. Endothelin-converting enzyme-1 increases in atherosclerotic mice: potential role of oxidized low density lipoproteins. Journal of lipid research, 50(3), pp.364-375.

10. Bateman, J.F., Boot-Handford, R.P. and Lamandé, S.R., 2009. Genetic diseases of connective tissues: cellular and extracellular effects of ECM mutations. Nature Reviews Genetics, 10(3), p.173 
11. Bianchini, F., Peppicelli, S., Fabbrizzi, P., Biagioni, A., Mazzanti, B., Menchi, G., Calorini, L., Pupi, A. and Trabocchi, A., 2017. Triazole RGD antagonist reverts TGF $\beta 1$-induced endothelial-tomesenchymal transition in endothelial precursor cells. Molecular and cellular biochemistry, 424(1-2), pp.99-110.

12. Richter, K. and Kietzmann, T., 2016. Reactive oxygen species and fibrosis: further evidence of a significant liaison. Cell and tissue research, 365(3), pp.591-605.

13. Querio, G., Antoniotti, S., Foglietta, F., Bertea, C.M., Canaparo, R., Gallo, M.P. and Levi, R., 2018. Chamazulene Attenuates ROS Levels in Bovine Aortic Endothelial Cells Exposed to High Glucose Concentrations and Hydrogen Peroxide. Frontiers in physiology, 9, p.246.

14. Morry, J., Ngamcherdtrakul, W. and Yantasee, W., 2017. Oxidative stress in cancer and fibrosis: Opportunity for therapeutic intervention with antioxidant compounds, enzymes, and nanoparticles. Redox biology, 11, pp.240-253.

15. Napolitano, F., Rossi, F.W., Pesapane, A., Varricchio, S., Ilardi, G., Mascolo, M., Staibano, S., Lavecchia, A., Ragno, P., Selleri, C. and Marone, G., 2018. N-Formyl Peptide receptors induce radical Oxygen Production in Fibroblasts Derived From systemic sclerosis by interacting With a cleaved Form of Urokinase receptor. Frontiers in immunology, 9, p.574.

16. Aicart Ramos, C., Papel del módulo carboxi-terminal de las óxido nítrico sintasas en la regulación de la síntesis de NO: caracterización del receptor nuclear E75, un sensor de óxido nítrico (Doctoral dissertation, Universidad Complutense de Madrid).

17. Ferrer, C.F.S., Peiró, C. and Rodríguez-Mañas, L., 2011. Disfunción endotelial asociada al envejecimiento vascular humano. Clínica e investigación en arteriosclerosis, 23(3), pp.135-139

18. Kerr, B.A., Ma, L., West, X.Z., Ding, L., Malinin, N.L., Weber, M.E., Tischenko, M., Goc, A., Somanath, P.R., Penn, M.S. and Podrez, E.A., 2013. Interference with AKT signaling protects against myocardial infarction and death by limiting the consequences of oxidative stress. Sciences Signalling, 6(287), pp.ra67-ra67.

19. Saadane, A., Masters, S., DiDonato, J., Li, J. and Berger, M., 2007. Parthenolide inhibits IкB kinase, $\mathrm{NF}-\mathrm{\kappa B}$ activation, and inflammatory response in cystic fibrosis cells and mice. American Journal of Respiratory Cell and Molecular Biology, 36(6), pp.728-736.

20. López-Bojorquez, L.N., 2004. La regulación del factor de transcripción NF- $\kappa$ B. Un mediador molecular en el proceso inflamatorio. Revista de investigación clínica, 56(1), pp.83-92.

21. Nafees, S., Rashid, S., Ali, N., Hasan, S.K. and Sultana, S., 2015. Rutin ameliorates cyclophosphamide induced oxidative stress and inflammation in Wistar rats: role of NFKB/MAPK pathway. Chemico-biological interactions, 231, pp.98-107.

22. Ohkita, M., Takaoka, M., Shiota, Y., Nojiri, R., Sugii, M. and Matsumura, Y., 2002. A nuclear factor$\kappa \mathrm{B}$ inhibitor BAY 11-7082 suppresses endothelin-1 production in cultured vascular endothelial cells. The Japanese Journal of Pharmacology, 89(1), pp.81-84.

23. Gomez Sandoval, Y.H., Emehdi Atef, M., Levesque, L.O., Li, Y. and B Anand-Srivastava, M., 2014. Endothelin-1 signaling in vascular physiology and pathophysiology. Current vascular pharmacology, 12(2), pp.202-214.

24. Valdez, N.F., 2013. Endotelina-1: vasoconstrictor intrínseco del endotelio vascular. Revista Med, 21(2), pp.42-56.

25. Sutton, G., Pugh, D. and Dhaun, N., 2019. Developments in the role of endothelin-1 in atherosclerosis-a potential therapeutic target? American journal of hypertension. pii: hpz091.

26. Lüscher, T.F., Barton, M. 2000. Endothelins and endothelin receptor antagonist: therapeutic considerations for a novel class of cardiovascular drugs. Circulation, 102, pp: 2434-40.

27. Rodríguez-Vita J, Ruíz-Ortega M, Rupérez M, Esteban V, Sánchez-López E, Plaza JJ et al. 2005. Endothelin-1, via ETA receptor and independently of transforming growth factor-beta, increases the connective tissue growth factor in vascular smooth muscle cells. Circulation Research, 97, 125-134.

28. Rodríguez-Pascual F, Busnadiego O and Gónzalez-Santamaría J. 2014. The profibrotic role of endothelin-1: is the door still open for the treatment of fibrotic diseases? Life Sciences, 118, 156-164. 